\title{
Gut
}

\section{Leading article}

\section{Aetiology and natural history of primary sclerosing cholangitis - a decade of progress?}

Primary sclerosing cholangitis is a chronic cholestatic liver disease that is characterised by an obliterative inflammatory fibrosis of the biliary tract. This chronic inflammation frequently results in bile duct obliteration, biliary cirrhosis, hepatic failure, and sometimes in cholangiocarcinoma.

Although the first description of primary sclerosing cholangitis was made a century ago by Hoffman ${ }^{1}$ in 1867, over the next 100 years the disease remained a medical rarity. The advent of endoscopic cholangiography in the 1970s, however, enabled the diagnosis to be made in an ever increasing number of patients. This led to the publication in 1980 of two reviews of large numbers of patients with primary sclerosing cholangitis from the Mayo Clinic ${ }^{2}$ and the Royal Free Hospital. ${ }^{3}$ These studies described the clinical, histological, and radiological features of the characteristic chronic cholestatic syndrome of primary sclerosing cholangitis. Interest was reawakened on both sides of the Atlantic, and since 1980 progress in our understanding of all aspects of this fascinating disease has been remarkable. ${ }^{46}$

\section{Relation with inflammatory bowel disease}

The close relation between inflammatory bowel disease and various hepatobiliary disorders is well established. In the last decade, however, a different concept of hepatobiliary disorder in inflammatory bowel disease has emerged. It is now apparent that the major hepatobiliary diseases seen in association with inflammatory bowel disease, pericholangitis, primary sclerosing cholangitis, cholangiocarcinoma, and most cases of chronic active hepatitis represent different aspects of the same spectrum of hepatobiliary disease - viz primary sclerosing cholangitis.

For many years the term 'pericholangitis' has been synonymous with involvement of the liver in inflammatory bowel disease. ${ }^{78}$ However, it has become clear that most patients with histological pericholantitis, defined as an inflammatory portal reaction with periductular inflammation and fibrosis, will have cholangiographic appearances diagnostic of primary sclerosing cholangitis. ${ }^{9} \mathrm{~A}$ minority of patients with ulcerative colitis will have persistently abnormal liver function tests together with histological appearances such as concentric fibrosis, but have normal bile ducts at cholangiography. The term 'small duct primary sclerosing cholangitis' has been proposed to replace the term 'pericholangitis' in this group of patients, as the evidence suggests that these conditions are all part of the same disease spectrum. Wee and Ludwig described two patients who progressed from small duct primary sclerosing cholangitis to develop extrahepatic biliary involvement. ${ }^{10}$ Chronic active hepatitis has been reported in association with ulcerative colitis. ${ }^{11}$ However, piecemeal necrosis on liver histology can accompany the classic bile duct changes of primary sclerosing cholangitis on cholangiography ${ }^{3}$ and it seems likely that most patients with chronic active hepatitis and inflammatory bowel disease will have either large or small duct primary sclerosing cholangitis.

The relation between primary sclerosing cholangitis and inflammatory bowel disease, particularly ulcerative colitis, is a very close one. Approximately $70 \%$ of all patients with primary sclerosing cholangitis have coexisting ulcerative colitis, ${ }^{2-4}$ and primary sclerosing cholangitis is the most common form of chronic liver disease found in ulcerative colitis, occurring in 3-10\% of patients. ${ }^{49}$ Three studies from different parts of the world have reviewed the clinical features of patients with ulcerative colitis and primary sclerosing cholangitis. ${ }^{2-4}$ The findings from all three have been remarkably consistent. Paradoxically, the colitis is usually total but symptomatically mild, often with no rectal bleeding, and characterised by prolonged remissions. Although the symptoms of ulcerative colitis usually develop before those of sclerosing cholangitis, in some patients the onset of primary sclerosing cholangitis may precede the symptoms of colitis by up to four years. The outcome of the hepatobiliary disease is completely unrelated to the activity, severity, or clinical course of the colitis. This is borne out by the fact that colectomy makes no difference to the clinical progression or mortality of patients with primary sclerosing cholangitis. ${ }^{12}$ Indeed, liver disease may develop some years after a total colectomy has been performed. ${ }^{312}$ The increased frequency of bile duct cancer, including carcinoma of the gall bladder, in patients with ulcerative colitis is well established, ${ }^{13}{ }^{14}$ with an estimated prevalence rate of $0.5 \%$. It is also clear that adenocarcinoma of the biliary system may develop in patients with longstanding either large or small duct primary sclerosing cholangitis and ulcerative colitis. ${ }^{3}{ }^{15}$ It is possible that all patients with ulcerative colitis who develop biliary cancer have underlying primary sclerosing cholangitis.

There are fewer reports of primary sclerosing cholangitis associated with Crohn's disease, and the prevalence of bile duct carcinoma is not increased in Crohn's disease. ${ }^{14}$ The explanation for these apparent differences in prevalence between the two diseases is unclear. 


\section{Aetiology}

The cause of primary sclerosing cholangitis is unknown, but any proposed aetiological factors must explain the close association with ulcerative colitis. Consequently, a number of hypotheses have been proposed to explain the association between colonic disease and biliary tract fibrosis, including ascending portal infection and abnormal bile acid metabolism. ${ }^{17}$ However, there is no evidence in favour of these aetiologies. ${ }^{18-23}$

Ludwig et $a l^{19}$ suggested that primary sclerosing cholangitis may be caused by a virus since cholangitis and biliary atresia may be induced in weanling mice, primates, and possibly also in human infants after infection with reovirus type III..$^{24}$ Serological studies ${ }^{25}$ have not shown any evidence of past or current infection with this virus, although other viruses may be involved.

Recent studies have suggested that genetic and immunological factors are important. Three sets of siblings from three families have been reported with primary sclerosing cholangitis and ulcerative colitis. ${ }^{26}$ The frequency of HLA $\mathrm{B} 8, \mathrm{DR} 3$ is much higher in primary sclerosing cholangitis patients than in control subjects. ${ }^{27} 28$ This finding not only confirms the role of genetic factors but also suggests that the disease may be immunologically mediated, as the HLA B8/ DR3 phenotype is associated with a number of autoimmune diseases such as autoimmune chronic active hepatitis, myaesthenia gravis, and thyrotoxicosis. Although the prevalence of HLA B8 DR3 is not increased in patients with ulcerative colitis, such a patient who is unfortunate enough to possess the HLA, B8, DR3 phenotype has a 10 fold increase in the relative risk of developing primary sclerosing cholangitis. These findings have been extended by the recent report of Prochazka et al..$^{29}$ These workers found that $100 \%$ of 29 primary sclerosing cholangitis patients referred for hepatic transplantation possessed the HLA-DRw52a antigen, which is on the DR3 B chain. This may represent the specific site on the HLA molecule related to the susceptibility to primary sclerosing cholangitis.

The possible importance of immunological factors has been emphasised by the number of recent reports that have shown humoral and cellular abnormalities in primary sclerosing cholangitis. The cellular immune abnormalities include low values of circulating suppressor $\mathrm{T}$ cells in serum,,$^{30}$ and large increases in the numbers of both suppressor and helper $T$ cells in the portal tracts in patients with primary sclerosing cholangitis, ${ }^{31}$ an inhibition of leukocyte migration in response to biliary antigens, ${ }^{32}$ and aberrant expression of HLA DR antigens on biliary epithelium at early stages of the disease.$^{33}$ Humoral immune defects include increased values of circulating immune complexes in blood, ${ }^{34}$ defective clearance of immune complexes, ${ }^{35}$ activation of the complement system, ${ }^{36}$ and circulating antibodies against neutrophil nuclei. ${ }^{37}$

Current evidence suggests that primary sclerosing cholangitis is an immunologically mediated disease, probably triggered in genetically susceptible subjects by acquired toxic or infectious agents that may gain access through the colon.

\section{Natural history and prognosis}

Recent studies have confirmed earlier reports ${ }^{2}{ }^{3}$ that symptomatic primary sclerosing cholangitis is often a severe progressive liver disease. This is borne out by the fact that it is one of the most common indications for transplantation. The average time between the onset of symptoms and death is approximately seven years with a range of 6 months - 15 years. In a study of 29 symptomatic patients, Lebovics $e t$ al found that $41 \%$ died or developed liver failure requiring liver transplantation during a mean follow up of 6.3 years. ${ }^{38}$
Similarly, the largest report from the Mayo Clinic found that $49 \%$ of 137 symptomatic patients died or developed liver failure during a mean follow up of $6 \cdot 2$ years. ${ }^{39}$

Most symptomatic patients die in hepatic failure after deepening cholestatic jaundice. However, approximately $20-30 \%$ of patients with longstanding primary sclerosing cholangitis die from the development of bile duct cancer which often follows a very aggressive course. Unfortunately, no risk factors which predict the primary sclerosing cholangitis patients who will develop carcinoma have been identified.

With the advent of liver transplantation, it has become important to identify prognostic factors to predict the risk of progression to liver failure and death. These factors would be useful in deriving survival models which can be used to identify individual primary sclerosing cholangitis patients at low, moderate, and high risk. A number of these models have already been constructed for primary biliary cirrhosis. Unfortunately, studies from different units have provided conflicting results. The Yale study was the first to use multivariate analysis. ${ }^{40}$ This showed that hepatomegaly and a serum bilirubin concentration $>25 \mathrm{mmol} / 1$ were the only independent discriminators of a poor prognosis. ${ }^{+0}$ In contrast, the Mayo Clinic, also using multivariate analysis, found that age, serum bilirubin concentration, blood haemoglobin concentration, presence or absence of inflammatory bowel disease, and histological stage on liver biopsy were independent predictors of high risk of dying. ${ }^{22}$ To add to the confusion, the Royal Free group identified serum bilirubin, age, and the site of biliary involvement as indicators of a poor prognosis, whereas disease localised to the intrahepatic ducts was associated with a favourable outcome. ${ }^{+1}$ The message from these variable results is that larger multicentre studies are needed.

The natural history of asymptomatic patients with primary sclerosing cholangitis is less clearcut. The diagnosis is made incidentally when a persistently raised alkaline phosphate activity is discovered, usually in a patient with ulcerative colitis. There has been controversy as to the relative number of asymptomatic patients who will progress and the rate of progression to symptomatic chronic liver disease. The Yale group described 11 asymptomatic primary sclerosing cholangitis patients observed for a mean follow up period of three years $^{43}$ : none of this small group developed symptoms. In addition, Aadland et al reported that 27 asymptomatic or minimally asymptomatic patients followed for a mean of 4.4 years showed no evidence of progression of liver disease. ${ }^{+2}$ Both studies were in keeping with an earlier report that primary sclerosing cholangitis may remain asymptomatic for many years. ${ }^{+3}$

A recent report from the Mayo Clinic describes the progress of 45 asymptomatic patients followed for a median period of 75 months. ${ }^{+}$Thirty four $(76 \%)$ developed evidence of disease progression and $14(31 \%)$ developed liver failure that resulted in death or referral for liver transplantation. These results were in agreement with the Royal Free group who reported 17 asymptomatic patients; 10 (59\%) showed clinical progression over a mean of three years. ${ }^{+1}$

How can these studies be equated? The Mayo Clinic and Royal Free Hospital are tertiary referral centres and, inevitably, new asymptomatic patients will be referred at a later stage in their disease process. Our own unpublished observations show that about one third of 35 asymptomatic patients have developed symptoms and two patients have died over a median follow up of five years. On balance, it seems that most asymptomatic patients will progress but that there may well be a subset who do not progress clinically over many years. As yet there are no risk factors that have been identified to predict which asymptomatic patients will go on to develop liver failure or cholangiocarcinoma. In the light of potential 
therapeutic intervention further studies are needed in this important area.

\section{Conclusion}

The last decade has seen major advances in our understanding in all aspects of primary sclerosing cholangitis. It is to be hoped that the next 10 years will be equally productive and indicate the infectious or toxic agent which triggers the immune mediated biliary destruction in genetically susceptible subjects. Undoubtedly, accurate survival models will be developed from multicentre data which will allow optimal timing of medical therapy and liver transplantation. In addition, further studies will be needed to predict which patients are at risk of developing cholangiocarcinoma.

R W CHAPMAN

Department of Gastroenterology,

Fohn Radcliffe Hospital,

Oxford $O X 39 D U$

1 Hoffman CEE. Verschluss der Gallenwege curch Verdickung der Wandungen. Arch Pathol Anat Physiol 1867; 49: 206-15.

2 Wiesner RH, LaRusso NF. Clinicopathologic features of the syndrome of primary sclerosing cholangitis. Gastroenterology 1980; 79: 200-6.

3 Chapman RW, Arborgh BA, Rhodes JM, et al. Primary sclerosing cholangitis a review of its clinical features, chalangiography and hepatic histology. Gut a review of its clini

4 Schrumpf E, Fausa O, Kolmannskog F, Elgjo K, Ritland S, Gjone E. Sclerosing cholangitis in ulcerative colitis. A follow-up study. Scand $\mathcal{F}$ Gastroenterol 1982; 17: 33-9.

5 Chapman RW. Primary sclerosing cholangitis. F Hepatol 1985; 1: 179-86.

6 Lindor KD, Wiesner RH, LaRusso NF. Recent advances in the management of primary sclerosing cholangitis Semin $L$ iv Dis 1987; 7: 322-7.

7 Mistilis SP. Pericholangitis and ulcerative colitis: I Pathology, aetiology and pathogenesis. Ann Intern Med 1965; 63: 1-16.

8 Mistilis SP, Skyring AP, Goulston SJM. Pericholangitis and ulcerative colitis: II clinical aspects. Ann Intern Med 1965; 63: 17-26.

9 Shepherd HA, Selby WS, Chapman RW, Nolan D, Barbatis C, McGee I O'D, Jewell DP. Ulcerative colitis and liver dysfunction. Quart $\mathcal{f}$ Med 1983; 52: 503-13.

10 Wee A, Ludwig J. Perichaolangitis in chronic ulcerative colitis: primary sclerosing cholangitis of the small ducts? Annal Int Med 1985; 102: 581-7.

11 Olsson R, Hulten L. Concurrence of ulcerative colitis and chronic active hepatitis. Scand $\mathcal{F}$ Gastroenterol 1975; 10: 331-5.

12 Cangemi JR, Wiesner RH, Beaver SJ, et al. The effect of proctocolectomy for chronic ulcerative colitis on the natural history of primary sclerosing cholangitis. Gastroenterology 1989; 96: 190-4.

13 Ritchie JK, Allan RN, Macartney J, et al. Biliary tract carcinoma associated with ulcerative colitis. $Q \mathcal{F}$ Med 1974 ; 43: 263-79.

14 Mir-Madjlessi SH, Farmer RG, Sivak MV. Bile duct carcinoma in patients with ulcerative colitis. Dig Dis Sci 1987; 32: 145-54.

15 Wee A, Ludwig J, Coffey RJ, et al. Hepatobiliary carcinoma associated with primary schlerosing cholangitis and chronic ulcerative colitis. Hum Pathol primary schlerosing

16 Warren KW, Athanassiales S, Monge JL. Primary sclerosing cholangitis. Am F Surg 1966; 111: 23-38.

17 Eade MN, Brooke BN. Portal bacteraemia in cases of ulcerative colitis submitted to colectomy. Lancet 1969; i: 1008-9.

18 Palmer KR, Duerden BI, Holdsworth CD. Bacteriological and endotoxin studies in cases of ulcerative colitis submitted to surgery. Gut 1980; 21: $851-4$
19 Ludwig J, Barham SS, LaRusso NF, Elveback LR, Wiesner RH, McCall JT. Morphologic features of chronic hepatitis associated with primary sclerosing cholangitis and chronic ulcerative colitis. Hepatology 1981; 1: 632-40.

20 Carey JB. Bile acids, cirrhosis and human evolution. Gastroenterology 1964; 46: $490-2$.

21 Dew MJ, Henegouwen GP, Huybregts AWM, Allan RN. Hepatotoxic effect of bile acids in inflammatory bowel disease. Gastroenterology 1980; 78: $1393-401$.

22 Holzbach RT, Marsh ME, Freedman MR, Fazio VW, Lavery IC, Jagelman DA. Portal vein bile acids in patients with severe inflammatory bowel disease. Gut 1980; 21: 428-35.

23 Siegel JH, Barnes S, Morris JS. Bile acids in liver disease associated with inflammatory bowel disease. Digestion $1977 ; 15: 469-81$.

24 Bangaru B, Morecki R, Glaser JH, Gartner LM, Horwitz MS. Comparative studies of biliary atresia in the human newborn and reovirus-induced cholangitis in weanling mice. Lab Invest 1980; 43: 452-62.

25 Minuk GY, Rascanin N, Paul RW, Lee PWK, Buchan K, Kelly JK. Reovirus type 3 infection in patients with primary biliary cirrhosis and primary sclerosing cholangitis. F Hepatol 1987; 5: 8-13.

26 Quigley EMM, LaRusso NF, Ludwig J, MacSween RNM, Birnie GG, Watkinson G. Familial occurrence of primary sclerosing cholangitis and ulcerative colitis. Gastroenterology 1983; 85: 1160-5.

27 Chapman RW, Varghese Z, Gaul R, Patel G, Kikinon N, Sherlock S. Association of primary sclerosing cholangitis with HLA-B8. Gut 1983; 24 : 38-41.

28 Schrumpf E, Fausa O, Forre O, et al. HLA antigens and immunoregulatory T cells in ulcerative colitis associated with hepatobiliary disease. Scand $\mathcal{F}$ Gastroenterol 1982; 17: 187-91.

29 Prochazka EJ, Terasaki PI, MinSik Park DVM, Goldtein LI, Busuttil RW. Association of primary sclerosing cholangitis with HLA-DRw52a. N Engl J Med 1990; 322: $1842-4$

30 Lindor KD, Wiesner RH, Katzman JA, LaRusso NF, Beaver SJ. Lymphocyte subsets in primary sclerosing cholangitis. Dig Dis Sci 1987; 32: 720-5.

31 Whiteside TL, Lasky S, Si L, VanThiel DH. Immunologic analysis of nomonuclear cells in liver tissues and blood or patients with primary sclerosing cholangitis. Hepatology 1985; 5: 468-74.

32 McFarlane IG, Wojcicka BM, Tsantoulas DC, Portmann BC, Eddleston ALWF, Williams R. Leucocyte migration inhibition in response to bilary ALWF, Willams R. Leucocyte migration inhibition in response to bilary
antigens in primary biliary cirrhosis, sclerosing cholangitis and other chronic antigens in primary biliary cirrhosis, sclerosing chola
liver diseases. Gastroenterology 1979; 76: 1333-40.

33 Chapman RW, Kelly P, Heryet A, Jewell DP, Fleming KA. Expression of HLA $=D R$ antigens on bile duct epighelium in primary sclerosing cholangitis. Gut 1988; 29: 422-7.

34 Bodenheimer HCJ, LaRusso NF, Thayer WR Jr, Charland C, Staples PJ, Ludwig J. Elevated circulating immune complexes in primary sclerosing cholangitis. Hepatology 1983; 3: 150-4.

35 Minuk GY, Angus M, Brickman CM, Lawley TJ, Frank MM, Hoofnagle JH, Jones EA. Abnormal clearance of immune complexes from the circulation of patients with primary sclerosing cholangitis. Gastroenterology 1985; 88: 166-70.

36 Senaldi G, Donaldson PT, Magrin S et al. Activation of the complement system in primary sclerosing cholangitis. Gastroenterology 1989; 97: 1430-4.

37 Snook JA, Chapman RW, Fleming K, Jewell DP. Anti-neutrophil nuclear antibody in ulcerative colitis, Crohn's disease and primary sclerosing cholangitis. Clin Exp Immunol 1989; 76: 30-4

38 Lebovics E, Palmer M, Woo J, Schaffner F. Outcome of primary sclerosing cholangitis. Arch Intern Med 1987; 147: 729-31.

39 Wiesner RH, Grambsch PM, Dickson ER, et al. Primary sclerosing cholangitis: natural history, prognostic factors and survival analysis. Hepatology $1989 ; 10: 430-6$.

40 Helzberg JH, Petersen JM, Boyer JL. Improved survival with primary sclerosing cholangitis. Gastroenterology 1987; 92: 1869-75.

41 Herrman R, Dooley J, Sherlock S, et al. Progression of asymptomatic primary sclerosing cholangitis. $\mathcal{F}$ Hepatol 1988; 7 (suppl): 539.

42 Aadland E, Schrumpf E, Fausa O, et al. Primary sclerosing cholangitis: a longterm follow-up study. Scand 7 Gastroenterol 1987; 22: 655-64.

43 Chapman RW, Burroughs AK, Bass NM, Sherlock S. Long-standing asymptomatic primary sclerosing cholangitis. Report of three cases. Dig Dis Sci 1981; 26: 778-82.

44 Porayko NK, Wiesner RH, LaRusso NF, Ludwig J, MacCarty RL, Steiner BL, Twomey CK, Zinsmeister AR. Patients with asymptomatic primary sclerosing cholangitis frequently have progressive disease. Gastroenterology 1990; 98: 1594-602. 